La actualidad de la radio

Florencia Halfon Laskman - Fernando Iranzo

Question/Cuestión, Vol. 2, N 66, Agosto 2020

ISSN 1669-6581

https://perio.unlp.edu.ar/ojs/index.php/question/index

IICom-FPyCS-UNLP

\title{
LA ACTUALIDAD DE LA RADIO
}

\section{THE PRESENT OF DE RADIO}

\section{Florencia Halfon Laskman}

Estudió periodismo en TEA, Desde muy joven recorrió estudios de radio y televisión, donde hizo producción, notas, móviles, y luego conducción. Fue conductora y columnista de Metro, 95,1, actualmente conduce "Ahora dicen", por Futurock.

Twitter: Flor Halfon Laksman @FlorHalfon

\section{Entrevista sonora por Fernando Iranzo}

Licenciado en Comunicación Social, Locutor Nacional № 12.555. Docente en la FPyCS desde 2000. Actualmente en comunicación de la Subsecretaría de Derechos Humanos, productor del programa BA con Derechos por Radio 
Provincia de Buenos Aires y realización integral del podcast Sintonía Pincharrata.

fa.iranzo@gmail.com

\section{Resumen}

La actualidad de la radio según Florencia Halfon Laskman, las mujeres en la radio. Radio y nuevas tecnologías.

\section{Palabras clave}

Radio, Actualidad, Centenario, Mujeres

\section{Abstract}

Interview with the journalist Florencia Halfon Laskman about the present of the radio.

\section{Key Words}

Radio, Present, Centennial, Women

\section{Enlace}

https://go.ivoox.com/rf/55560762 